\title{
Spatial Predictions of Cover Attributes of Rangeland Ecosystems Using Regression Kriging and Remote Sensing
}

\author{
Jason W. Karl \\ Author is Spatial Ecologist, Idaho Chapter of The Nature Conservancy, 950 W Bannock St, Suite 210, Boise, ID 83702, USA.
}

\begin{abstract}
Sound rangeland management requires accurate information on rangeland condition over large landscapes. A commonly applied approach to making spatial predictions of attributes related to rangeland condition (e.g., shrub or bare ground cover) from remote sensing is via regression between field and remotely sensed data. This has worked well in some situations but has limited utility when correlations between field and image data are low and it does not take advantage of all information contained in the field data. I compared spatial predictions from generalized least-squares (GLS) regression to a geostatistical interpolator, regression kriging (RK), for three rangeland attributes (percent cover of shrubs, bare ground, and cheatgrass [Bromus tectorum L.]) in a southern Idaho study area. The RK technique combines GLS regression with spatial interpolation of the residuals to improve predictions of rangeland condition attributes over large landscapes. I employed a remote-sensing technique, object-based image analysis (OBIA), to segment Landsat 5 Thematic Mapper images into polygons (i.e., objects) because previous research has shown that OBIA yields higher image-to-field data correlations and can be used to select appropriate scales for analysis. Spatial dependence, the decrease in autocorrelation with increasing distance, was strongest for percent shrub cover (samples autocorrelated up to a distance [i.e., range] of $19098 \mathrm{~m}$ ) but present in all three variables (range of $12646 \mathrm{~m}$ and $768 \mathrm{~m}$ for bare ground and cheatgrass cover, respectively). As a result, RK produced more accurate results than GLS regression alone for all three attributes when predicted versus observed values of each attribute were measured by leaveone-out cross validation. The results of RK could be used in assessments of rangeland conditions over large landscapes. The ability to create maps quantifying how prediction confidence changes with distance from field samples is a significant benefit of regression kriging and makes this approach suitable for landscape-level management planning.
\end{abstract}

\section{Resumen}

El buen manejo de los pastizales exige tener una información exacta sobre la condición de los pastizales dentro de las grandes extensiones. Un enfoque comúnmente aplicado para hacer predicciones espaciales de los atributos relacionados con la condición de los pastizales (ejemplo, arbustos o cobertura del suelo desnudo) de los sensores remotos es mediante la regresión entre el campo y los datos de los sensores remotos. Estos han funcionado bien en algunas situaciones pero tienen limitada utilidad cuando las correlaciones entre campo e imagen de datos son bajas y no toman ventaja de toda la información contenida en lo datos de campo. Yo comparé las predicciones espaciales de una regresión generalizada de mínimos cuadrados (GLS) a un interpolador geoestadistico, regresión kriging (RK), para tres atributos de los pastizales (porcentaje de cobertura de arbustos, suelo desnudo y cheatgrass [Bromus tectorum L.]) en un área de estudio en el sur de Idaho. La técnica RK combina, la regresión con interpolación especial de residuales GLS para mejorar las predicciones de la condición de los pastizales sobre grandes áreas. Empleé una técnica de teledetección, basada en objetos y análisis de imágenes (OBIA), al segmento de los polígonos de imágenes Landsat 5 Thematic Mapper (ejemplo objetos) debido a que previas investigaciones han proporcionado correlaciones más altos OBIA de los datos imagen-campo y que pueden usarse para seleccionar apropiadamente escalas para análisis. La dependencia espacial, y la disminución en la auto correlación con el aumento de la distancia, fue aun más robusto por el porcentaje de cobertura arbustiva (muestras auto correlacionadas hasta una distancia [ejemplo., rango] de $19098 \mathrm{~m}$ ), pero estuvieron presente en las tres variables (rangos de $12646 \mathrm{~m}$ y $768 \mathrm{~m}$ para suelo desnudo y cobertura de cheatgrass, respectivamente). Como resultado RK produjo calores más exactos que la regresión GLS sola para los tres atributos cuando se predijeron versus valores observados de cada uno de los atributos que se midieron pero dejando uno afuera para la validación cruzada. Los resultados de RK pueden usarse en la evaluación de la condición de los pastizales dentro de grandes áreas. La habilidad de crear mapas que cuantifican cómo cambia la seguridad de la predicción con la distancia de las muestras de campo, es un importante beneficio de la regresión kriging y convierte este enfoque adecuado para una planeación de manejo a nivel paisaje.

Key Words: Bromus tectorum, geostatistics, Idaho, landscape-scale assessment, shrub cover, statistical modeling

$\overline{\text { Research was funded in part by the M.J. Murdock Charitable Trust, the Lava Lake Foundation for }}$ Science and Conservation, and The Nature Conservancy's Rodney Johnson and Katherine Ordway Science Endowment.

Correspondence: Jason Karl, US Department of Agriculture-Agricultural Research Service Jornada Experimental Range, PO Box 30003 MSC 3JER, New Mexico State University, Las Cruces, NM 88003, USA. Email: jkar@@nmsu.edu

Manuscript received 8 June 2009; manuscript accepted 27 December 2009.

\section{INTRODUCTION}

Sound rangeland management and decision making requires accurate information related to the status and trend of soils, hydrology, and/or vegetation over large landscapes (National Research Council 1994). Many of these factors are measures of continuous attributes like percent shrub cover, bare ground, or 
biomass. For example, when managing sage grouse (Centrocercus urophasianus) habitat, percent cover and height of sagebrush (Artemisia spp.) and grasses are important (Connelly et al. 2000; Crawford et al. 2004). Grazing impacts are frequently measured by utilization (Holechek et al. 2001) or amount of bare ground (Pickup et al. 1994). Stocking levels are determined, in part, by the amount of available forage biomass (Holechek 1988; Hunt and Miyake 2006).

The use of remote sensing to map or make spatial predictions of rangeland attributes has been widely explored, in part because field sampling is usually not an effective means for collecting data over large areas (Hunt et al. 2003). Interpolation between field sampling locations is also difficult in heterogeneous landscapes. The hope with remote sensing is that sensor technologies and processing methods will yield an efficient method for sampling large landscapes and making reliable spatial predictions of rangeland attributes.

In general, remote-sensing information related to rangeland attributes comes from either a model-driven or a data-driven approach (Schott 2007). Model-driven approaches are used for developing image indices (e.g., the normalized difference vegetation index [NDVI] or fraction of photosynthetically active radiation) and are based on theoretical models of how electromagnetic radiation is reflected or absorbed by vegetation and validated through simulation exercises and field trials. Data-driven approaches, on the other hand, relate field observations to image values through statistical models or classifiers. One data-driven approach to making spatial predictions of rangeland attributes from remotely sensed imagery has been to develop a statistical model that relates the field measurements to the image band values, ratios of band values, or imagery-derived vegetation indices at those points (Forster 1980; Dymond et al. 1992; McKenzie and Ryan 1999; Qi et al. 2002). The resulting statistical model is then applied to all the pixels in the image. While this works well in some situations, it has limited utility when the correlation between field and image data is low, and it does not take full advantage of all the information that can be obtained from the field samples.

Geostatistical interpolators can also be used to make spatial predictions of continuous variables using field samples. Predicted values for unsampled locations are determined by a combination of the surrounding samples weighted by their distance to the unknown location (Fortin and Dale 2005). Kriging, originally developed by Krige (1966) for mineral exploration, is one of the most widely used geostatistical interpolators because of its fidelity to the sample data (i.e., prediction errors are minimized close to sample points) and ability to generate spatial predictions of standard error (see the following discussion). In short, kriging uses a model of the spatial dependence between samples (i.e., how autocorrelation changes as a function of distance between samples) as well as the distance to neighboring sample points to create estimates at unknown locations (Bailey and Gatrell 1995). The number and distribution of sample points affect the scale of predictions that can be made via statistical interpolators. This is especially true for kriging, as sample points of varying distances apart are needed to estimate spatial autocorrelation. Given the cost and time required to collect field samples, it is often difficult to obtain enough samples to make spatial predictions at a scale that is useful to rangeland managers using statistical interpolators alone.

Hybridized approaches have been developed that combine regression models with geostatistical predictors. Such approaches yield tighter integration of field and remote-sensing data, making better use of high-cost field observations and improving the accuracy of remote sensing-derived map products. Several studies have found that these hybridized methods perform better than either approach used separately (Odeh and McBratney 1994; Odeh et al. 1995; Goovaerts 1997; Hengl et al. 2007).

One hybridized approach is a derivation of kriging called regression kriging (RK), which first seeks to establish a linear relationship between the field samples and a secondary data set, typically a remotely sensed image, and then uses kriging to predict the value of the regression model residuals to improve the prediction (Odeh and McBratney 1994; Odeh et al. 1995; Hengl et al. 2004, 2007). In RK, the predicted value at an unsampled location is the sum of the regression prediction and the kriged residuals. The technique of RK has been used successfully in many applications, including mapping precipitation (Lloyd 2005) and leaf-area index of boreal forests (Berterretche et al. 2005) and predicting soil properties (Odeh et al. 1995; Lopez-Granados et al. 2005; Yemefack et al. 2005) but has not yet seen wide application in rangeland management.

RK has the potential to be a broadly useful technique for making spatial predictions of aspects of rangeland condition because it provides an approach to tightly integrating field and remote sensing data to get the most information out of each source. My objective was to demonstrate the utility of the RK approach to provide information on attributes of rangeland ecosystems in a southern Idaho landscape. I compare the RK method to linear regression between field and satellite image data for percent shrub, bare ground, and cheatgrass (Bromus tectorum L.) cover in a southern Idaho landscape (Fig. 1). Finally, I provide discussion on the uses and limitations of the RK technique to providing information for rangeland management and getting the most information out of available data sources.

\section{REGRESSION KRIGING}

A brief introduction of the concepts of geostatistical predictors as they apply to kriging is offered prior to discussing RK. For more detailed discussion of geostatistical prediction, see Bailey and Gatrell (1995), Goovaerts (1997), and Fortin and Dale (2005).

Kriging, like other geospatial predictors, has at its core one of the fundamental rules of geography that "near things are more related than distant things" (Tobler 1970, p. 236). In practical terms, this means that observations of a variable at nearby locations are not independent (i.e., they are spatially autocorrelated). In most cases, the spatial autocorrelation is highest when two observations are very close and decreases as the distance between observations grows until at some point the observations can be considered independent. In the context of classical statistics (Rice 2007), autocorrelation is problematic, and efforts are made to ensure independence of sample data. In 


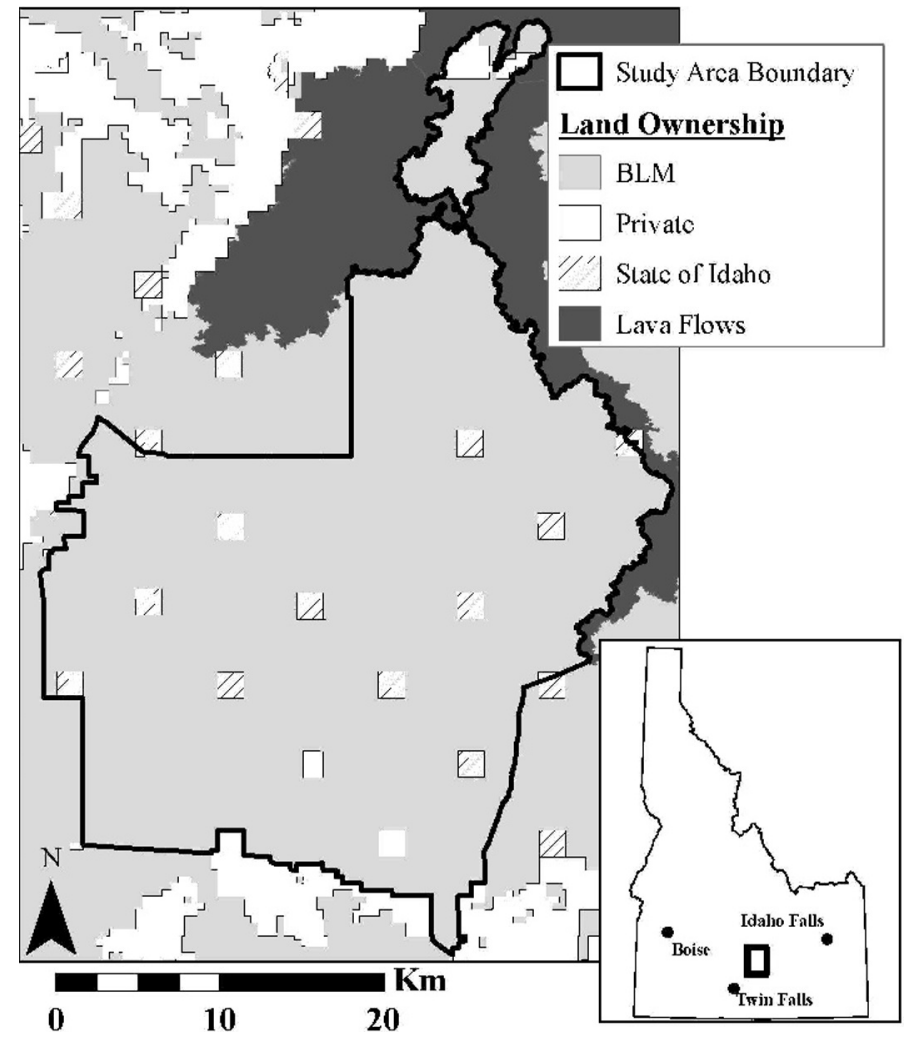

Figure 1. The Wildhorse study area in southern Idaho. (BLM, Bureau of Land Management.)

geostatistics, however, spatial autocorrelation is useful for improving predictions if the autocorrelation can be characterized.

Kriging makes predictions of a variable at unknown locations by taking a weighted average of the variable's value from sample locations where it was measured. The weights are selected to minimize prediction error variance using 1) the distance that each sample point is to the unknown location and 2) the spatial autocorrelation of the sample locations (Hengl et al. 2007).

Considering a sample of $n$ observations of a rangeland variable (e.g., percent cover of shrubs) taken at known locations $s_{i}$ that can be written as $z\left(s_{1}\right), z\left(s_{2}\right), \ldots, z\left(s_{n}\right)$, the predicted value of the variable at an unknown location is:

$$
\hat{z}\left(s_{0}\right)=\sum_{i=1}^{n} \lambda_{i} \cdot z\left(s_{i}\right)
$$

where $\hat{z}\left(s_{0}\right)$ is the predicted value at the unknown location $s_{0}$ and the $\lambda_{i}$ are the weights applied to the $i$ observations. The optimal weights for any unknown location are found by way of a variance/covariance matrix of the observations and the spatial covariance of the observations to the unknown point. For an unbiased kriging prediction, the sum of the weights must equal one (i.e., $\sum_{i=1}^{n} \lambda_{i}=1$ ), but weights can be negative for distant observations (Deutsch 1996). The spatial covariances between known and unknown locations, of course, are not known and must be estimated via a model of the spatial dependence (i.e., the change in covariance with distance between observations) of the target variable.

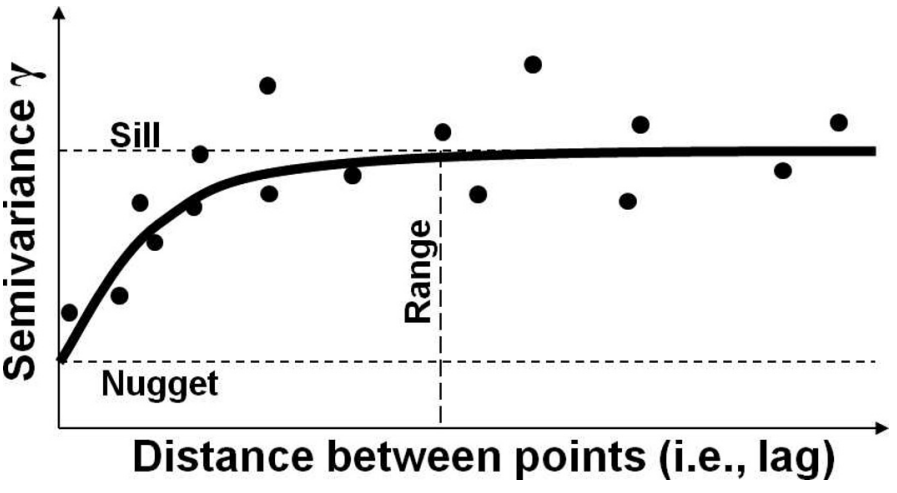

Figure 2. Example of a sample (i.e., empirical) variogram (black points) and the variogram model (heavy solid line).

Spatial dependence is quantified using semivariance, a measure of dissimilarity between two locations that is a function of the distance, $h$, between them (Fortin and Dale 2005). Semivariance is calculated between all pairs of observations as:

$$
\hat{\gamma}(h)=\frac{1}{2 n(h)} \sum_{i=1}^{n}\left[z\left(s_{i}\right)-z\left(s_{i}+h\right)\right]^{2}
$$

where $\hat{\gamma}(b)$ is the estimate of semivariance for all observations separated by a distance $h$, and $n(h)$ is the number of points separated by a distance of $h$ (Fortin and Dale 2005). In practice, distances are combined into distance groups (i.e., lags) to make calculation easier. A plot of estimated semivariance over a range of lag distances is called an empirical semivariogram and is an expression of the spatial dependence of the target variable (Fig. 2). A model that is fit to the empirical variogram (see Bailey and Gatrell 1995; Fortin and Dale 2005) estimates the spatial covariances needed to find the kriging weights. The semivariogram model specifies 1) the portion of the total observed variance $\left(\sigma^{2}\right)$ that cannot be explained by lag distance (i.e., the nugget), 2) the proportion of the total observed variability (i.e., the sill) that can be explained by distance (i.e., nugget-to-sill ratio), and 3) the maximum distance over which spatial autocorrelation is present (i.e., the range).

Kriging has a number of assumptions that must be met before it can be successfully used. One assumption of kriging is that the predictor variables are normally distributed (for discussion of normality assumptions in kriging, see Bailey and Gatrell 1995; Hengl et al. 2004). Often, data must be transformed to achieve a linear relationship between the predictor and response variables. Predicted values from kriging can be easily back-transformed, but problems exist with back-transforming estimates of variance (Hengl et al. 2004).

A second assumption to which the results of kriging are very sensitive is that the data must be spatially stationary or, in other words, lack any kind of first-order trend with respect to the geography of the study area. The presence of a significant trend in the data may result in misspecification of the spatial dependence necessary to perform kriging and bias the predictions.

Several methods have been proposed for "detrending" data prior to kriging (Cressie 1993; Bailey and Gatrell 1995). An understanding of a few of these methods is helpful to avoid 
confusion and clarify how RK works. Bailey and Gatrell (1995) and Fortin and Dale (2005) give overviews of many of the different kriging variations. Kriging performed on data that have no geographic trend is called "simple kriging" if the mean is known or "ordinary kriging" if the mean is unknown (Bailey and Gatrell 1995). Universal kriging incorporates estimation of trend along with the spatial prediction. Many authors agree that the term "universal kriging" should be reserved for cases where the trend is modeled as a function of only the positions of the sample points (i.e., using latitude and longitude coordinate values; Hengl et al. 2004). If other variables are used to estimate trend, the procedure is known as kriging with external drift (KED). With KED, the equations for making predictions from sample data are solved all at once via generalized least squares (Hengl et al. 2004). However, the trend and residuals can be fitted separately and the results summed together to obtain the spatial prediction. This procedure was called RK by Odeh and McBratney (1994; see also Odeh et al. 1995) and has the advantage that it is more stable than KED and can be used with a variety of different regression methods (Hengl et al. 2004).

Regression kriging starts with a standard multiple regression predictor for determining the relationship between measurements of a dependent variable, $z$, and a set of $p$ predictor variables-designated with $q$ rather than the standard notation of $x$ to avoid confusion with coordinate values (Hengl et al. 2007)—taken at known locations $s_{i}$ :

$$
z\left(s_{i}\right)=\sum_{k=0}^{p} \beta_{k} \cdot q_{k}\left(s_{i}\right)+e_{i}
$$

where $\beta_{k}$ are the regression coefficients and $e_{i}$ is the residual, accounting for the difference between the predicted and observed value. In RK, the regression coefficients are usually found using generalized least squares (GLS) in order to account for spatial autocorrelation of the residuals (Cressie 1993; Hengl et al. 2004). Typically, reflectance values or metrics derived from ratios of image bands (e.g., NDVI) from satellite imagery are used as the predictor variables. Hengl et al. (2004) recommended using a linear combination of the satellite imagery such as principal components to improve the regression results.

If the residuals from GLS exhibit spatial dependence, then an estimate of the value of the regression residual at unknown locations can be made using ordinary kriging. To accomplish this, semivariances are calculated over a range of lag distances from the GLS model residuals using Equation 2 above, and an empirical semivariogram is constructed. A semivariogram model is fit and used to derive the kriging weights for estimating the residual at unknown locations.

The RK predictor for a rangeland variable at an unmeasured location, $\hat{z}\left(s_{0}\right)$, then becomes the sum of the GLS regression prediction and the predicted residual:

$$
\hat{z}\left(s_{0}\right)=\sum_{k=0}^{p} \hat{\beta}_{k} \cdot q_{k}\left(s_{0}\right)+\sum_{i=1}^{n} \lambda_{i} \cdot e\left(s_{i}\right)
$$

where $q_{k}\left(s_{0}\right)$ is the value of the $k$ th predictor variable at the unknown location, the $\lambda_{i}$ are the kriging weights determined from the $i$ known locations using the variogram model of the GLS-model residuals, and $e\left(s_{i}\right)$ are the GLS-model residual value at point $i$ (Hengl et al. 2007).

The variance of the RK prediction consists of the variance of the GLS regression model plus the variance of the kriged residuals (see Cressie 1993; Hengl et al. 2004). This composite variance reflects the increase in prediction uncertainty as the location gets farther away from the observation point and farther away from the regression mean. When using transformed data, variance estimates of RK cannot be easily backtransformed because they may not be symmetric around the regression plane (Hengl et al. 2004). Hengl et al. (2004), however, provided an example of how $(1-\alpha) \%$ confidence intervals could be constructed from RK predictions with logistic-transformed data. This example can be adapted for other transformations.

An alternative kriging method for making spatial predictions using covariates is cokriging. With cokriging, predictions are made using the spatial dependence of the primary variable of interest sampled at a limited number of locations; spatial dependence of a secondary, correlated variable that is mapped continuously across the study area; and a "cross-covariogram" that describes the cross correlation between the primary and secondary variables (Bailey and Gatrell 1995). Nash et al. (1992) used cokriging to map vegetative cover in rangelands from measurements of soil moisture. Cokriging, however, is a more complicated technique than RK, requiring more parameters to be estimated and generally producing results that are similar to RK (Knotters et al. 1995; Hudak et al. 2002).

\section{STUDY AREA}

I applied the RK approach to making spatial predictions of rangeland attributes in the 97308-ha Bureau of Land Management (BLM) Wildhorse Allotment in southern Idaho (Fig. 1; lat $43.028^{\circ} \mathrm{N}$, long $113.864^{\circ} \mathrm{W}$ ). The Wildhorse Allotment lies within the Snake River plain and is partially within the Craters of the Moon National Monument. Physiographically, the study area is mostly flat plateaus or gently rolling hills, ranging in elevation from $1272 \mathrm{~m}$ to $1557 \mathrm{~m}$. Precipitation ranges from $24.9 \mathrm{~cm}$ to $32.6 \mathrm{~cm}$ based on the PRISM map of average annual precipitation from 1971 to 2000 (PRISM Group, Oregon State University, http://www. prismclimate.org, created 16 June 2006).

Current vegetation communities are dominated by a mosaic of mountain big sagebrush (Artemisia tridentata Nutt. subsp. vaseyana [Rydb.] Beetle), three-tip sage (Artemisia tripartita Rydb.), and Basin big sagebrush (Artemisia tridentata Nutt. subsp. tridentata). Principal understory grasses are bluebunch wheatgrass (Pseudoroegneria spicata [Pursh] A. Löve) and Idaho fescue (Festuca idahoensis Elmer). Cheatgrass (Bromus tectorum L.) abundance is variable within the study area, reaching high densities in disturbed sites and sites that have frequently burned. Dominant ecological sites within the study area are loamy Basin big sagebrush/bluebunch wheatgrass, Wyoming big sagebrush (Artemisia tridentata Nutt. subsp. wyomingensis Beetle \& Young//bluebunch wheatgrass, threetip sage/Idaho fescue, and sandy Basin big sagebrush/needleand-thread grass (Hesperostipa comata [Trin. \& Rupr.] Bark- 
worth)-indian ricegrass (Achnatherum bymenoides [Roem. \& Schult.] Barkworth; US Department of Agriculture-Natural Resources Conservation Service 2003).

The study area has had an active fire history with 18 wildfires over the past $20 \mathrm{yr}$, with eight of those being greater than 200 ha. Over the past $20 \mathrm{yr}, 80.04 \%$ of the Wildhorse Allotment has burned. The frequent, large fires in this area have contributed to the spread of cheatgrass and other invasive species in the allotment.

The majority of the Wildhorse Allotment is in public ownership with the BLM being the largest single land steward, managing approximately 93317 ha $(95.8 \%)$ of the study area. Approximately 1305 ha $(1.3 \%)$ of the study area is in private ownership and 2843 ha $(2.9 \%)$ managed by the state of Idaho. The main land use in the study area is cattle and sheep grazing.

\section{METHODS}

For this study, I employed a remote sensing technique called object-based image analysis (OBIA) to prepare the image data for the regression analyses. In OBIA, contiguous pixels in an image are first grouped into objects (i.e., polygons) in such a way that the pixels within an object are more similar than the pixels in neighboring objects (Baatz and Schäpe 2000; Burnett and Blaschke 2003). I used the multiresolution segmentation method developed by Baatz and Schäpe (2000) as implemented in the Definiens Developer 7.0 program (Definiens AG, Munich, Germany). In the multiresolution segmentation method, neighboring pixels are initially joined together to form an object. Subsequently, neighboring objects that are similar (according to the parameters set) are merged into larger objects until a threshold of heterogeneity is reached within the object. The multiresolution segmentation method accepts a number of parameters that control how pixels and objects are merged into larger objects. Color and shape parameters control the degree to which the objects are defined by spectral versus textural information and the compactness of the objects, respectively. A unitless scale parameter controls the size (i.e., scale) of the objects by specifying how dissimilar neighboring objects can be and still be merged.

A unique feature of OBIA as opposed to other methods of scaling-up satellite imagery is that highly distinct objects (e.g., disturbed areas and water bodies), even though they may be small, can persist as image objects while the overall scale of the surrounding objects becomes larger. This mimics the way that humans perceive the surface of the earth when interpreting aerial imagery (Burnett and Blaschke 2003). By selection of the appropriate segmentation parameter sets, objects defined through OBIA can approximate habitat patch structures and be formed into scale hierarchies that correspond to different levels of ecosystem organization (Wu 1999; Blaschke et al. 2002; Wu and David 2002).

For this study, I created a set of image objects from Landsat Thematic Mapper 5 (TM) imagery and derived mean and standard deviation of pixel values for each object (see the following discussion). Regressions were then run against these values for each object. Finally, the kriging predictions were made for the centroids of the TM image objects and the predicted values assigned to the entire image object.

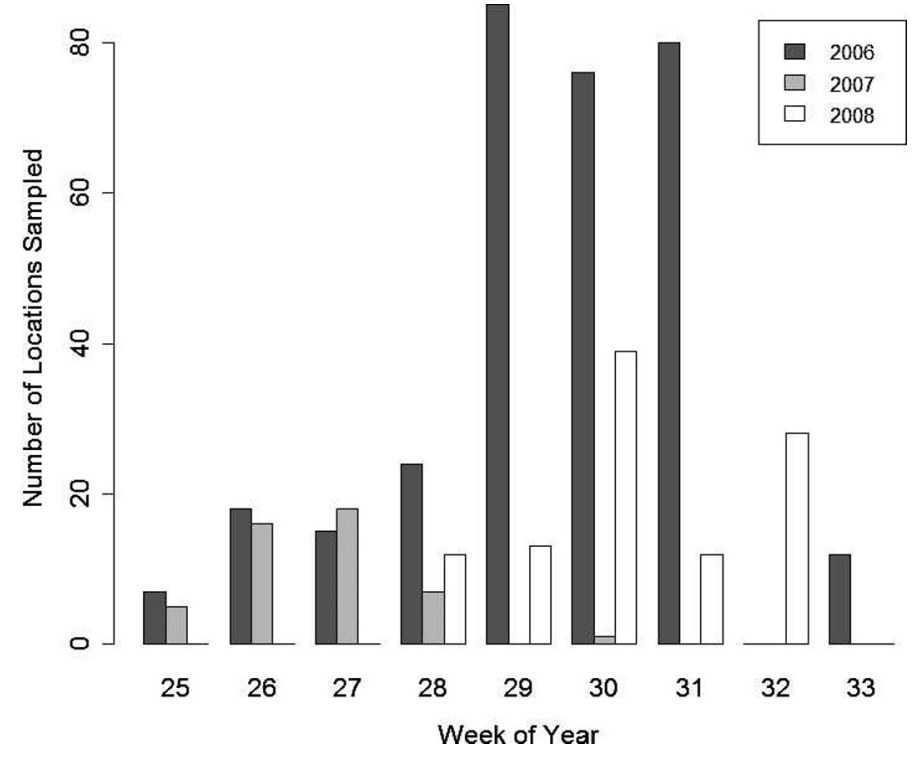

Figure 3. Histogram of number of field points collected by week of the year for each of the $3 \mathrm{yr}$ of sampling.

\section{Field Data Collection}

I used field data that were collected by the Shoshone District BLM (G. Mann and J. Russel, BLM, unpublished data, 2009). The original purpose of these data was to look at the effects of restoration activities and wildland fire in the Wildhorse Allotment. The study area was divided up into 21 units based on the road network within the allotment. These units were used as strata, and random sampling locations were selected within each stratum. Sampling sites were located randomly within each stratum. The density of sampling locations within each stratum varied depending on how much of the area had recently burned and whether postfire restoration activities had been implemented in the unit. Random site placement ensured that points would be located at irregular intervals from each other, making it possible to estimate spatial autocorrelation for kriging. A total of 625 random locations were generated for sampling.

Between 21 June 2006 and 6 August 2008, sampling was conducted at 468 locations. The majority of sampling took place in 2006 (317 sites sampled across eight units) and 2008 (104 sites sampled across eight units). One stratum was not sampled at all, and seven of the eight strata sampled in 2008 had less than their full number of their randomly generated locations sampled. This was done to achieve a good distribution of sample points across the entire study area. Sampling took place during an 8-wk window each year, but sampling effort was not consistent across this time period (Fig. 3). Strata were opportunistically selected for sampling, but, once selected, all sites within the unit were sampled (or all that were going to be sampled) before moving on to another unit.

To sample percent cover at each sample location, two $73-\mathrm{m}$ (240-foot) transects were set. Precision for transect length was $0.15 \mathrm{~m}$. Percent cover of plant species was recorded using the line-point-intercept method described by Herrick et al. (2005) with the exception that 25 readings were taken on each transect. The location of each sample point was recorded with a global positioning system and differentially corrected. 
Table 1. Summary statistics from the 346 field observations for the three percent cover variables being predicted across the Wildhorse area: shrub, bare ground, and cheatgrass.

\begin{tabular}{lccc}
\hline & \% Shrub & \% Bare ground & \% Cheatgrass \\
\hline Minimum & 0.00 & 0.00 & 0.00 \\
Maximum & 28.00 & 51.85 & 56.00 \\
Median & 1.41 & 8.66 & 11.57 \\
Mean & 3.53 & 10.74 & 12.22 \\
Standard deviation & 5.06 & 8.34 & 7.93 \\
\hline
\end{tabular}

Of the 468 original sites, I excluded 122 because the sites had burned between the date they were sampled and when the satellite imagery was collected (see the following discussion). For the remaining 346 observation sites, I calculated percent shrub cover as the number of sample points where any shrub species was encountered in any of the canopy layers or as a basal hit divided by 50 (Table 1). For the purposes of rangeland assessment and monitoring, bare ground is considered land surface not covered by vegetation, rock, or litter (Bedell 1998; Pellant et al. 2005). Percent bare ground cover was calculated as the proportion of the 50 points where no plant canopy was intercepted and the soil surface was recorded as exposed soil (Herrick et al. 2005). Cheatgrass cover was calculated as the number of points along the transect where cheatgrass was encountered in any of the canopy layers or as a basal hit divided by 50 .

For the Wildhorse Allotment, the 8-wk sampling window each year encompassed a large portion of the growing season. Accordingly, significant changes in percent cover between points sampled early in the season and those sampled later due to plant growth might have occurred, especially if there were strong elevation or precipitation gradients in the study area. The Wildhorse Allotment, however, has relatively gentle topography with only a slight increase in elevation and precipitation from south to north. Regressions of percent cover for shrubs, bare ground, and cheatgrass by Julian date for each year showed that, with two exceptions, there were no significant trends in percent cover over the duration of the field season (Table 2). Slight trends were detected for percent bare ground in 2006 and percent cheatgrass cover in 2008 . However, the Julian date of the sampling accounted for such a small portion of the observed variability in the field data $\left(R^{2}=0.05\right.$ and $R^{2}=0.09$ for 2006 bare ground and 2008 cheatgrass, respectively). Additionally, the trends were apparent in only $1 \mathrm{yr}$ for each variable, and I concluded that the presence of these minor trends would not have a large impact on the relationship between the field and image data.

\section{Image Acquisition and Processing}

I acquired a TM satellite image from the US Geological Survey's Earth Resource Observation and Science (USGS EROS) Data Center (http://earthexplorer.usgs.gov) for the study area from 11 July 2008. The study area was entirely within one TM scene from path 40, row 30, of the USGS EROS World Reference System-2. Geometric and radiometric corrections were applied by USGS EROS (L1G level of processing) to remove sensor distortions and to standardize pixel dimensions. The scene was orthorectified to $1-\mathrm{m}$ color aerial photography
Table 2. Test for trend in cover estimates over the course of the sampling period each field season. Slope $(\beta)$ is the coefficient from a linear regression model between the Julian date of the sampling and the percent cover variable of interest. Reported $P$ values are for the test of slope $(\beta)=0$.

\begin{tabular}{lccc}
\hline & $\%$ Shrub & \% Bare ground & $\%$ Cheatgrass \\
\hline 2006 & & & \\
$\quad$ Slope $(\beta)$ & 0.0000 & 0.0008 & 0.0006 \\
$P$ value & 0.8550 & $<0.0001$ & 0.0699 \\
$R^{2}$ & 0.0002 & 0.0585 & 0.0073 \\
2007 & & & \\
$\quad$ Slope $(\beta)$ & 0.0010 & 0.0027 & 0.0000 \\
$P$ value & 0.1580 & 0.2960 & 0.9710 \\
$R^{2}$ & 0.0225 & 0.0026 & 0.0000 \\
2008 & & & \\
$\quad$ Slope $(\beta)$ & 0.0010 & -0.0048 & -0.0029 \\
$P$ value & 0.1470 & 0.5700 & 0.0011 \\
$R^{2}$ & 0.0109 & 0.0066 & 0.0903 \\
\hline
\end{tabular}

and a one-third-arc-second digital elevation model using ERDAS Imagine (http://www.erdas.com). Within the study area, the orthorectified TM image had a positional root-meansquare error (RMSE) of less than half a pixel $(15 \mathrm{~m})$. This was deemed acceptable accuracy because sample locations were to be associated with OBIA-derived image objects (i.e., collections of relatively similar, adjacent pixels) and not individual pixels (see the following discussion). I applied a dark-object subtraction method to correct for some of the effects of atmosphere (Chavez 1996), and converted the image values to top-of-theatmosphere reflectance.

The original multispectral bands of an image are highly correlated, and this can be undesirable when segmenting the image in OBIA (Navulur 2007). I used the tasseled-cap transformation (Jensen 1996) to obtain a set of bands having low correlations with each other. The tasseled-cap transformation is a linear combination of the original image bands that is defined such that each of the output bands has a specific interpretation (Crist and Kauth 1986). Tasseled-cap coefficients must be defined for each sensor, atmospheric correction algorithm, and data format (e.g., reflectance, radiance, 8-bit digital numbers). The number of tasseled-cap bands possible equals the number of original bands from the sensor. The first tasseled-cap band is interpreted as brightness of the land surface. The second band is interpreted as "greenness" and correlates highly with plant photosynthetic activity. The third band is interpreted as wetness and correlates with vegetation and soil moisture. Band 4, in most instances, captures much of the noise in the image and generally is discarded. Band 5 contains useful information (i.e., is not a noise band) but usually does not have a clear interpretation.

I used bands 1, 2, 3, and 5 of the tasseled-cap transformed image with the multiresolution segmentation algorithm in Definiens Developer version 7.0 (Definiens AG, Munich, Germany) to create a set of image objects for the study area. The scale parameter of the segmentation algorithm was set so that the median size of the image objects consisted of at least 20 pixels. All other segmentation parameters were left at default 
values. Segmentation resulted in 13646 image object polygons with a median size of 5.22 ha (range $0.09-459.81$ ha). To each image object polygon, I assigned the mean and standard deviation of the pixels within the object for each band. The image object polygons and their attribute values were exported to a geographic information system layer. I intersected the image object polygon layer with the sample points to obtain a table that had the field measurements, tasseled-cap image values, and coordinates for each sample point. This table became the input for the statistical analysis. Additionally, I created a point layer of geometric centroids from the image object polygons that was used in the kriging analyses to predict the value of each image object.

Feitosa et al. (2006) and Addink et al. (2007) showed that there may be a particular scale of image segmentation that maximizes the prediction accuracy of a variable being mapped (i.e., an optimal scale). At scales below this optimal level (including pixel-level analysis not using OBIA), regression does not account for all the spatial variability expressed in a semivariogram of the original field observations. In such cases, the model residuals will show spatial autocorrelation, and RK will yield better results than standard regression (Karl and Maurer 2010). Optimal segmentation levels may vary for different rangeland attributes, depending on the nature of their spatial autocorrelation (Addink et al. 2007). Because RK can extract more information using the spatially autocorrelated regression residuals, it offers a way to achieve similar results from different sets of image objects for a rangeland attribute without having to worry about finding a near-optimal segmentation level. A practical value of this, at least for studies involving vegetation cover, is that the same segmentation level can be used to make predictions for multiple rangeland attributes even though the optimal segmentation level might be different for each attribute. This holds as long as the segmentation level is below the optimal level for each attribute. For this reason, I chose a small-scale parameter for segmentation that was likely to be below the optimal level for any of the three attributes under consideration.

\section{Statistical Analysis}

For the sake of exploring the benefits of RK for making spatial predictions, I compared the results of the RK technique to a standard GLS regression approach. Each method was repeated for percent shrub, bare ground cover, and cheatgrass cover. All statistical analyses were done in R 2.7.2 (http://www.r-project. org) using the CAR package for data transformations (Fox 2002), the NLME package for GLS modeling (Pinheiro and Bates 2000), and the GSTAT package for variogram modeling and kriging (Pebesma 2004).

The regression analysis started with 13 predictor variables: mean pixel values and standard deviation of pixel values by image object for tasseled cap bands 1,2, 3, and 5 and a soiladjusted total vegetation index (Marsett et al. 2006). In addition, $\mathrm{I}$ included $\mathrm{X}$ and $\mathrm{Y}$ coordinate values relative to the center of the study area and the product of the relative $\mathrm{X}$ and $\mathrm{Y}$ coordinates.

To perform the ordinary kriging on the GLS regression residuals, there should be no trend in the residuals that can be explained by other predictor variables. The presence of a trend could lead either to misspecification of the spatial autocorrelation in the regression residuals or apparent spatial autocorrelation that is related not to the variable of interest but to another variable. This could happen if, for instance, there was a trend in percent cover with respect to increasing elevation or fire history. In this case, a variogram of the residuals might reflect more the spatial autocorrelation of elevation or fire history than of the vegetation. The Wildhorse study area showed slight increases in elevation and precipitation from south to north. The incorporation of $\mathrm{X}$ and $\mathrm{Y}$ coordinate values and their product in the regression model is a way to account for these correlated trends across the study area. No significant correlation was found between the shrub, bare ground, or cheatgrass GLS model residuals and time since last fire or number of recorded fires. Therefore, the residual variograms should reflect the spatial autocorrelation of the variables being considered.

Through exploratory data analysis, I checked each variable for normality and performed transformations as necessary. While the tasseled-cap transformation achieves independence between the output bands, it does not guarantee the normal distribution of pixel values assumed for linear regression and kriging. The only variables requiring transformation were those recording the standard deviation in tasseled-cap pixels. A square-root transformation was sufficient to meet normality assumptions for these variables. All variables were rescaled to range between zero and one. I identified outliers (i.e., those points with a value more than two standard deviations from the mean) for each variable and investigated each one individually using the study data sets and 1-m color aerial photography. If the investigation revealed that the outlier was atypical of the range of variability found in the study area or another problem was identified, the point was excluded; otherwise, it was retained.

I used GLS to establish the linear relationship between the independent and dependent variables. Percent shrub, bare ground, and cheatgrass cover were modeled separately. Initial models included all independent variables. The only betweenvariable interaction considered was between the $\mathrm{X}$ and $\mathrm{Y}$ coordinate values. I used a backward-stepwise process to find a parsimonious model for each variable (Table 3). At this point, the regression coefficients for the final model were taken and applied to the full set of image objects to obtain the GLS-only prediction for the Wildhorse area.

The GLS method supports specification of the covariance and spatial autocorrelation between the sample points (Cressie 1993). Employing this option, however, requires a reiteration of the regression modeling because a variogram needs to be constructed from a set of model residuals to estimate initial spatial autocorrelation. The GLS-only results were run without specifying any covariance structure. For RK, I constructed an empirical variogram from this initial model's residuals and defined a variogram model consisting of a nugget, range, and sill. The form of variogram model (e.g., spherical, exponential, Gaussian) that fit the empirical variogram best was selected. I used an exponential variogram model for percent shrub cover and a spherical variogram model for percent bare ground and cheatgrass cover. Exponential variogram models reach their sill only as distance increases to infinity. For such variogram model forms that do not have a sill, it is common to measure their effective range as the distance at which the variogram reaches 
Table 3. Generalized least-squares models for percent shrub, bare ground, and cheatgrass (Bromus tectorum L.) cover as predicted from Landsat Thematic Mapper 5 satellite data aggregated into image objects.

\begin{tabular}{|c|c|c|c|c|c|c|}
\hline \multirow[b]{2}{*}{ Variable } & \multicolumn{2}{|c|}{$\%$ Shrub } & \multicolumn{2}{|c|}{$\%$ Bare ground } & \multicolumn{2}{|c|}{$\%$ Cheatgrass } \\
\hline & Coefficient & $P$ value & Coefficient & $P$ value & Coefficient & $P$ value \\
\hline Intercept mean & 0.6147 & $<0.0001$ & 5.878 & 0.0045 & 0.233 & $<0.0001$ \\
\hline TCap 1 & - & - & 0.272 & $<0.0001$ & - & - \\
\hline TCap 3 & 0.715 & $<0.0001$ & 0.238 & $<0.0001$ & -0.270 & $<0.0001$ \\
\hline TCap 5 & -0.937 & $<0.0001$ & - & - & 0.285 & $<0.0001$ \\
\hline SATVI & 1.0614 & $<0.0001$ & - & - & - & - \\
\hline \multicolumn{7}{|c|}{ Standard deviation } \\
\hline TCap 1 & -0.2147 & 0.0005 & - & - & - & - \\
\hline TCap 2 & -0.1466 & 0.0104 & -0.195 & 0.0003 & 0.216 & 0.0002 \\
\hline TCap 3 & 0.0983 & 0.0270 & 0.135 & 0.0020 & - & - \\
\hline \multicolumn{7}{|l|}{ Positional } \\
\hline ReIX & 0.2397 & 0.0001 & -23.852 & 0.0060 & - & - \\
\hline RelY & - & - & -64.671 & 0.0059 & -0.181 & 0.0003 \\
\hline RelX•RelY & - & - & 77.117 & 0.0060 & - & - \\
\hline$R^{2}$ & 0.5311 & - & 0.299 & - & 0.306 & - \\
\hline
\end{tabular}

95\% of its sill (Deutsch and Journel 1998). I calculated effective range for the exponential variogram model and actual range for the spherical models.

The variogram model was used to create the variance/ covariance matrix for a second GLS run. The updated regression coefficients from this final model were used to make the spatial predictions on the full image object data set (Table 3). I used the residuals from the final GLS model to construct a second variogram and define the variogram model that would be used in the kriging portion of the spatial predictions.

I used R's GSTAT package (Pebesma 2004) to attribute each image object with continuous cover fractions according to the RK results. The kriging routine in GSTAT used the GLS model and the variogram model defined from the GLS residuals to predict the value of each of the three percent cover attributes at the centroids of all the image objects. The kriging routine in GSTAT was also used to produce a variance estimate for each regression-kriged location that was the sum of the variance of the regression estimate and the kriging variance.

Because I used a square-root transformation on my response variables, I squared the model predictions to back-transform my GLS regression and RK predictions. Goovaerts (1997) noted that the use of transformations with regression kriging can lead to values in the results that are outside the physical range of the response variable (e.g., negative values, percentages greater than 100). Hengl et al. (2004) suggested masking out or manually correcting such values. Accordingly, I limited percent cover predictions to between zero and $100 \%$. I also calculated and mapped $95 \%$ confidence intervals for the regression kriging results for both percent cover variables using the following formula adapted from Hengl et al. (2004):

$$
\hat{Z}_{ \pm 0.95}\left(S_{0}\right)=\left(\hat{Z}\left(S_{0}\right) \pm 1.96 \cdot \hat{\sigma}\left(S_{0}\right)\right)^{2}
$$

where $\hat{Z}\left(S_{0}\right)$ is the predicted value at location $S_{0}$, and $\hat{\sigma}\left(S_{0}\right)$ is the standard deviation of the estimated value at location $S_{0}$.

\section{Evaluating Performance of Predictions}

RMSE was a convenient measure of performance that could be easily derived and directly compared for each method. I used a leave-one-out cross-validation method to calculate RMSE for the GLS regression model and RK predictions. In leave-one-out cross validation, a sample point is omitted and a value predicted for that point's location. The omitted point is then replaced, another point is omitted, and predictions are made again. This process is repeated until all points have been omitted. The differences between the predicted and observed values when each point is omitted are collected and used to calculate RMSE as:

$$
\mathrm{RMSE}=\sqrt{\frac{\sum_{i=1}^{n}\left(z\left(S_{i}\right)-\hat{z}\left(S_{i}\right)\right)^{2}}{n}}
$$

where $z\left(S_{i}\right)$ was the observed value for location $S_{i}$ and $\hat{z}\left(S_{i}\right)$ was the predicted value for the same location over all $n$ points. I also used the cross-validation results to construct plots of predicted versus observed values for each prediction method on each variable.

The RMSE can be standardized by total standard deviation of the observed samples as a way to compare results between variables of different types (Hengl et al. 2004). An advantage to using standardized RMSE is that there is no need to backtransform the data. Hengl et al. (2004) proposed that a standardized RMSE of around $40 \%$ is a satisfactory accuracy for predicting landscape attributes with regression kriging. I calculated standardized RMSE for each prediction method on each variable to compare results. 
A) Shrub Residual Variogram

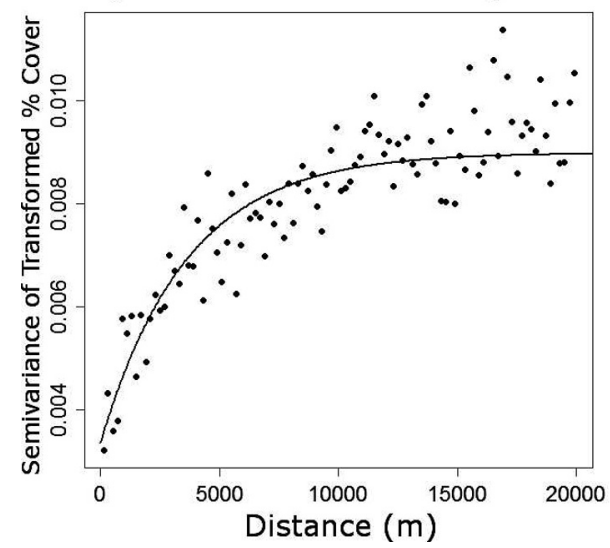

B) Bare Ground Residual Variogram

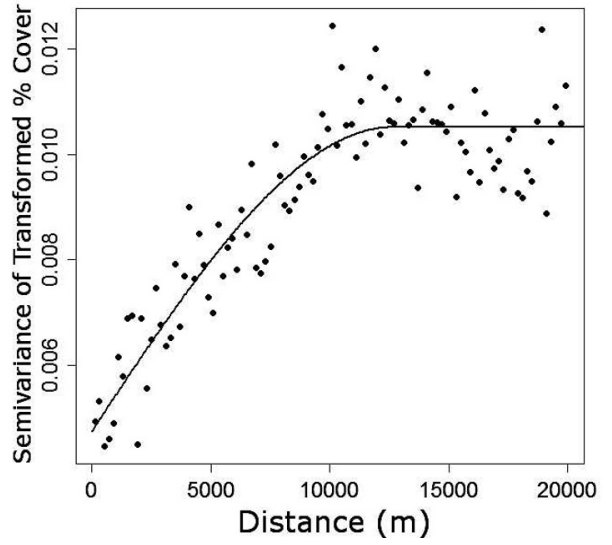

C) Cheatgrass Residual Variogram

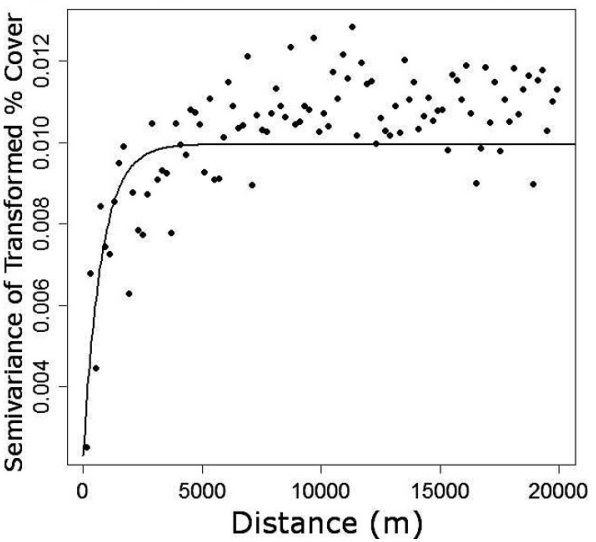

Figure 4. Empirical variogram and variogram models for the residuals of the generalized least-squares regression models. Semivariance is expressed in transformed units squared. A, For percent shrub cover, an exponential model was used with a nugget, or variance of the residuals unexplained by distance, of 0.0034 . The sill of the variogram model, or the total variance of the residuals, was 0.0090 . An exponential model approaches its sill as distance goes to infinity. Accordingly, the effective range for an exponential model is defined by convention as the point at which the variogram model reaches $95 \%$ of its sill (Deutsch and Journel 1998). The effective range for the variogram model, or distance at which locations are no longer spatially autocorrelated, was $19098 \mathrm{~m}$. B. For percent bare ground cover, a spherical variogram model was used with a nugget, sill, and range of $0.0047 \mathrm{~m}, 0.0105 \mathrm{~m}$, and $12646 \mathrm{~m}$, respectively. C, For percent cheatgrass cover, a spherical variogram model was used with a nugget, sill, and range of $0.0023 \mathrm{~m}, 0.0100 \mathrm{~m}$, and $768 \mathrm{~m}$, respectively.

\section{RESULTS}

The GLS models for each of the three rangeland attributes had adjusted $R^{2}$ values ranging from 0.299 for percent bare ground cover to 0.531 for percent shrub cover (Table 3). Spectral (i.e., average pixel values per image object) and textural (i.e., standard deviation of pixel values per image object) were important in predicting cover of all three variables. For percent shrub cover, there was a significant trend from east to west. For percent cheatgrass cover, there was a significant trend from north to south, and for bare ground cover, there was a secondorder trend in both latitude and longitude. Factoring in the geographic trends in addition to the variables derived from the TM imagery and image objects is necessary to meet the stationarity requirements for kriging the model residuals.

The empirical variograms of the GLS model residuals showed differing amounts of spatial autocorrelation in the residuals for each rangeland attribute. For percent shrub cover, the nugget-tosill ratio (an expression of the proportion of the variability in the residuals cannot be explained by distance) was 0.377 (Fig. 4A). The distance at which residuals of the shrub cover GLS model were no longer spatially autocorrelated was $19098 \mathrm{~m}$. Percent bare ground cover had a higher nugget-to-sill ratio, 0.448, meaning that less of the variability in bare ground cover could be explained by distance (Fig. 4B). The range of the bare ground residuals, however, was lower at $12646 \mathrm{~m}$, indicating that the distance of spatial autocorrelation for bare ground was shorter. The residuals for the percent cheatgrass cover model had the lowest nugget-to-sill ratio at 0.023 , suggesting that values of residuals could be projected to unknown locations nearby the field points (Fig. 4C). However, this spatial autocorrelation was operating over a relatively short distance of $768 \mathrm{~m}$.

Cross-validation run on the GLS model and the regression kriging showed that in all cases, regression kriging led to better predictions for the three rangeland attributes (Table 4). For percent shrub cover, correlation between the original observa- tions and the cross-validated GLS predictions was 0.7018 (Fig. 5A), whereas the correlation for the cross-validated RK predictions was 0.7353 (Fig. 5B). Calculated RMSE decreased from $3.63 \%$ for the GLS model to $3.42 \%$ for the RK predictions. For percent bare ground cover, cross-validation correlations were 0.5800 and 0.6475 for the GLS and RK predictions, respectively (Figs. 5C and 5D). The RMSE for bare ground cover went from $6.78 \%$ for GLS to $6.35 \%$ for RK. Finally, crossvalidation correlations for percent cheatgrass cover were 0.5092 and 0.5900 for the GLS and RK predictions, respectively (Figs. 5E and 5F). Estimated RMSE decreased from $6.87 \%$ for the GLS model predictions to $6.42 \%$ for the RK predictions.

Standardized RMSE gives a way to compare between different models (Hengl et al. 2004), and a standardized RMSE of 0.4 or less is generally indicative of a good prediction. Standardized RMSE values were less than 0.4 only for the percent shrub cover predictions (Table 4). In all cases, though, RK produced smaller standardized RMSE than the GLS model alone, and in the case of percent bare ground cover, the

Table 4. Cross-validation results for the generalized least-squares (GLS) regression model and the regression kriging model (RK) predictions of percent shrub, bare ground, and cheatgrass cover. $R^{2}$ is the correlation between the predicted and observed values from the cross validation.

\begin{tabular}{llccc}
\hline & Model & $R^{2}$ & RMSE $^{1}$ & Standardized RMSE \\
\hline \% Shrub cover & GLS & 0.4925 & $3.63 \%$ & 27.15 \\
& RK & 0.5407 & $3.42 \%$ & 25.55 \\
\% Bare ground cover & GLS & 0.3356 & $6.78 \%$ & 81.28 \\
& RK & 0.4173 & $6.35 \%$ & 54.23 \\
\% Cheatgrass cover & GLS & 0.2593 & $6.87 \%$ & 54.40 \\
& RK & 0.3481 & $6.42 \%$ & 50.90 \\
\hline
\end{tabular}

${ }^{1}$ RMSE indicates root-mean-square error, and standardized RMSE is the RMSE divided by the standard deviation of the observed values after Hengl et al. (2004). 
A)

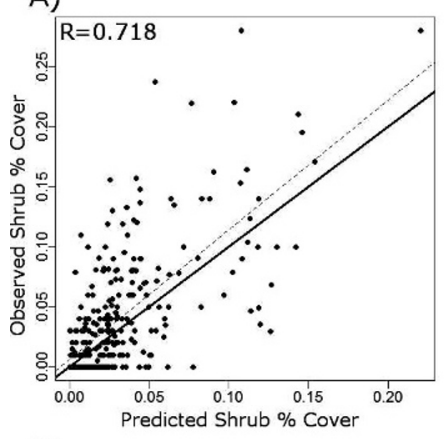

C)

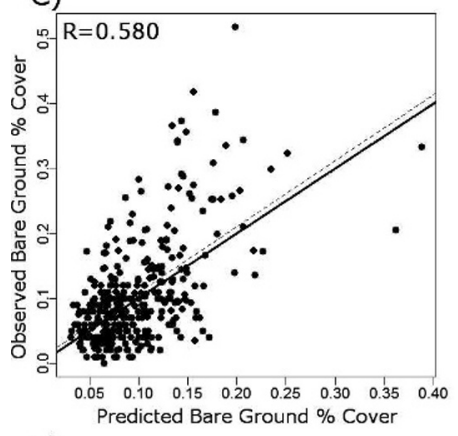

E)

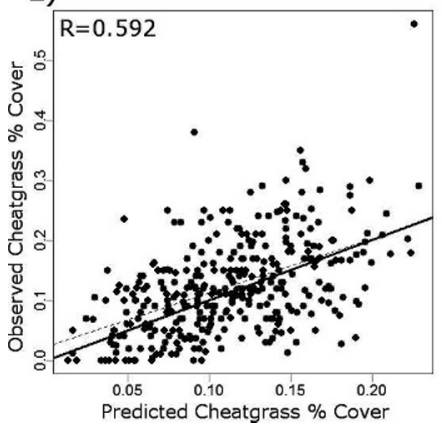

B)

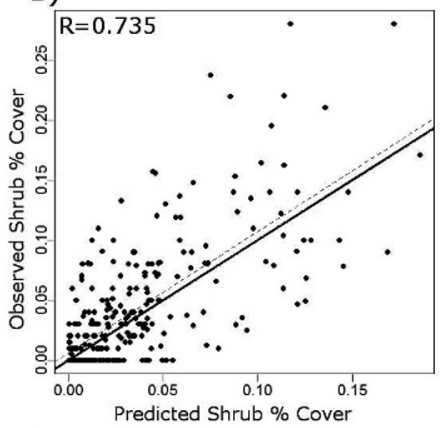

D)

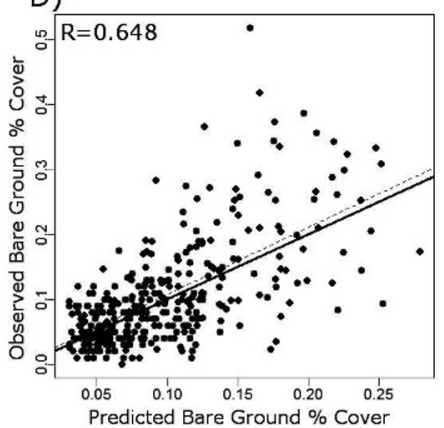

F)

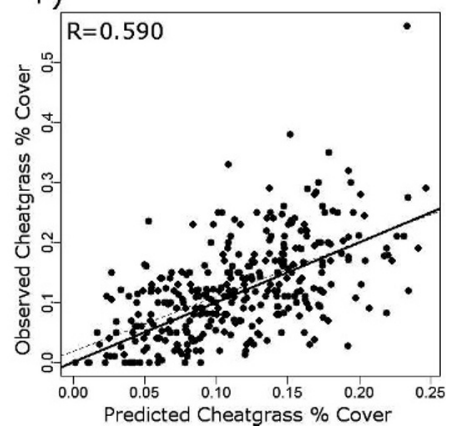

Figure 5. Plots of predicted versus observed values for the generalized least-squares (GLS) regression and regression kriging (RK) models. A, GLS regression percent shrub cover model (root-mean-square error $[$ RMSE] $=3.63 \%$; standardized RMSE $=0.272$ ). B, RK percent shrub ground cover model (RMSE $=3.42 \%$; standardized RMSE $=0.256$ ). C, GLS regression percent bare ground cover model (RMSE $=6.78 \%$; standardized RMSE $=0.8128$ ). D, RK percent bare ground cover model $(\mathrm{RMSE}=6.34 \%$; standardized $\mathrm{RMSE}=0.5413) . \mathrm{E}, \mathrm{GLS}$ regression percent cheatgrass cover model (RMSE $=6.87 \%$; standardized RMSE $=0.544)$. F, RK percent cheatgrass cover model $(\mathrm{RMSE}=6.42 \%$; standardized RMSE $=0.509$ ).

difference in standardized RMSE between GLS and RK was large (81.28 for GLS vs. 54.23 for RK).

While the overall model fit and accuracy levels of the GLS and RK predictions may be similar for a rangeland attribute, the spatial distribution of the predictions may vary considerably. For percent shrub cover, most of the study area was predicted to have less then $5 \%$ shrub cover (Table 5). The mean of the field shrub cover measurements was $3.53 \%$ $(\mathrm{SD}=5.06$; Table 1). RK predicted a somewhat lower proportion of the landscape as in the less-than-5\%-cover category than did GLS (Table 5). The spatial distribution of percent shrub cover from RK showed a more aggregated pattern than the GLS predictions (Fig. 6). The higher degree of aggregation

Table 5. Proportion of the study area in five percent cover categories for predictions of percent cover of the three rangeland attributes make via generalized least-squares regression (GLS) and regression kriging (RK).

\begin{tabular}{ccccccc}
\hline & \multicolumn{7}{c}{ Proportion of study area in \% cover category } \\
\cline { 2 - 7 } & $<5 \%$ & $5-10 \%$ & $10-15 \%$ & $15-20 \%$ & $20-25 \%$ & $>25 \%$ \\
\hline Shrub cover & & & & & & \\
RK prediction & 0.606 & 0.212 & 0.134 & 0.025 & 0.008 & 0.015 \\
$\quad$ Lower 95\% Cl & 0.630 & 0.224 & 0.108 & 0.019 & 0.005 & 0.013 \\
Upper 95\% Cl & 0.584 & 0.200 & 0.152 & 0.037 & 0.010 & 0.017 \\
GLS prediction & 0.691 & 0.222 & 0.059 & 0.012 & 0.002 & 0.015 \\
Lower 95\% Cl & 0.722 & 0.209 & 0.045 & 0.009 & 0.001 & 0.015 \\
Upper 95\% Cl & 0.654 & 0.236 & 0.074 & 0.018 & 0.002 & 0.015 \\
Bare ground & & & & & & \\
RK prediction & 0.112 & 0.330 & 0.249 & 0.182 & 0.082 & 0.045 \\
Lower 95\% Cl & 0.157 & 0.334 & 0.236 & 0.179 & 0.061 & 0.034 \\
Upper 95\% Cl & 0.071 & 0.319 & 0.263 & 0.182 & 0.107 & 0.058 \\
GLS prediction & 0.153 & 0.378 & 0.286 & 0.117 & 0.029 & 0.036 \\
Lower 95\% Cl & 0.192 & 0.397 & 0.263 & 0.093 & 0.021 & 0.033 \\
Upper 95\% Cl & 0.124 & 0.347 & 0.303 & 0.143 & 0.042 & 0.040 \\
Cheatgrass cover & & & & & & \\
RK prediction & 0.130 & 0.337 & 0.335 & 0.153 & 0.040 & 0.006 \\
Lower 95\% Cl & 0.180 & 0.364 & 0.315 & 0.119 & 0.018 & 0.003 \\
Upper 95\% Cl & 0.094 & 0.294 & 0.340 & 0.188 & 0.074 & 0.010 \\
GLS prediction & 0.112 & 0.306 & 0.375 & 0.145 & 0.044 & 0.017 \\
Lower 95\% Cl & 0.143 & 0.339 & 0.358 & 0.123 & 0.025 & 0.013 \\
Upper 95\% Cl & 0.083 & 0.272 & 0.365 & 0.189 & 0.068 & 0.023 \\
\hline
\end{tabular}

${ }^{1} \mathrm{Cl}$ indicates confidence interval.

in the RK predictions is a product of the spatial autocorrelation of the regression residuals. For bare ground, the majority of the study area was predicted to have between $5 \%$ and $15 \%$ cover of bare ground (Table 5). The mean bare ground measurement across the field observations was 10.74 ( $\mathrm{SD}=8.34$; Table 1 ). For bare ground cover, the RK method yielded slightly higher predictions on average over much of the landscape (Table 5). The spatial distribution for percent bare ground cover was also more aggregated for the RK than for the GLS predictions (Fig. 7). The long range associated with the percent bare ground model residuals led to the aggregation that is apparent in the RK predictions. Finally, both the GLS regression and the RK method predicted the majority of the study area to be between $5 \%$ and $15 \%$ cover of cheatgrass (Table 5). The mean cover of cheatgrass found in the field samples was $12.22 \%$ $(\mathrm{SD}=7.93$; Table 1). In the case of cheatgrass, the RK predictions were generally lower than the GLS predictions. The spatial distribution of cheatgrass was largely similar between the GLS regression and RK methods (Fig. 8). This is due to the short range of spatial autocorrelation in the cheatgrass regression residuals.

\section{DISCUSSION}

The results demonstrate that regression kriging can increase the accuracy of spatial predictions of rangeland variables over regression-based predictors alone. In some cases, like percent 


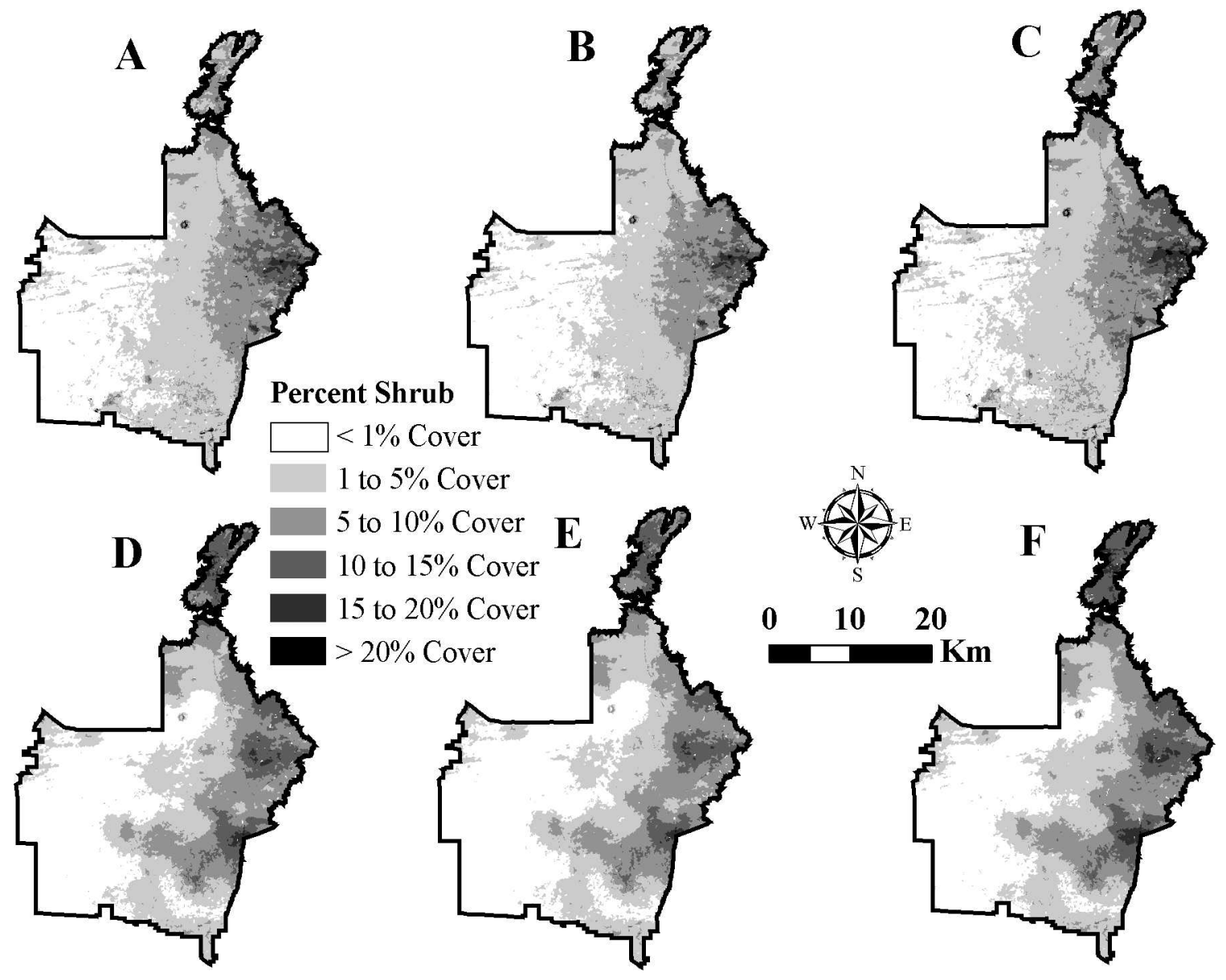

Figure 6. Spatial predictions of percent shrub cover in the Wildhorse area. A, Generalized least-squares (GLS) regression prediction. B, GLS lower 95\% confidence interval limit. C, GLS upper 95\% confidence interval limit. D, Regression kriging (RK) prediction. E, RK lower 95\% confidence interval limit. F, RK upper $95 \%$ confidence interval limit.

bare ground, the difference between a standard regression approach and RK can be large. However, this may not always be the case. Percent cover measurements from a different Idaho study area showed no significant spatial autocorrelation, and RK gave no better predictions than GLS (J. W. Karl and K. Colson, unpublished data, 2008). This may be because there was little spatial autocorrelation in the rangeland attributes to begin with or, more likely, because there were not enough field samples to detect and model the spatial autocorrelation.

This speaks to an important point to consider, namely, that geostatistical predictors, including regression kriging, often carry a higher implementation cost than standard regressionbased methods. Sufficient samples must be collected to estimate the variable's spatial autocorrelation with a variogram model. A general rule of thumb used among geostatisticians is that a minimum of 100 sample points is needed to construct a reliable variogram model (Webster and Oliver 1991), although the number of points needed to characterize spatial dependence is scale dependent (e.g., a higher number of samples would be needed if fine-scale predictions are to be made over a large area). In addition to the number of points, the distribution of the points in the study area is also important. Because variance of the regression-kriged predictor increases away from known locations, one would ideally want good coverage of sample points across the study area. However, a regular point spacing prevents estimation of spatial autocorrelation at lag distances shorter than the distance between observation points, so it is also desirable to have some points located close to each other in order to characterize short-range spatial autocorrelation. Lark (2002), through simulation studies, found that the nature of the spatial autocorrelation of the variable being mapped influenced the optimal configuration of sample points for estimating the variogram. Variables showing spatial dependence over long ranges can be sampled effectively with regularly spaced sampling schemes. Variables exhibiting short-range spatial dependence are best sampled by scattered clusters of points. In the case where there is no a priori knowledge on the nature of the spatial dependence of a variable, sampling along linear transects was deemed the most efficient for estimating spatial dependence from the field observations. Webster and Oliver (2007) advocated that when data are to be collected to estimate spatial dependence of a variable, a multistage or nested hierarchical sampling design that produces a distribution of sample locations that have a variety of distances between points (i.e., some sites are close together, some are far apart) would be efficient at collecting data to estimate semivariance.

While RK yielded improvements in the standardized RMSE for all three variables, the predictions for percent bare ground and cheatgrass cover were still higher than the $40 \%$ rule proposed by Hengl et al. (2004). However, given the RMSE 


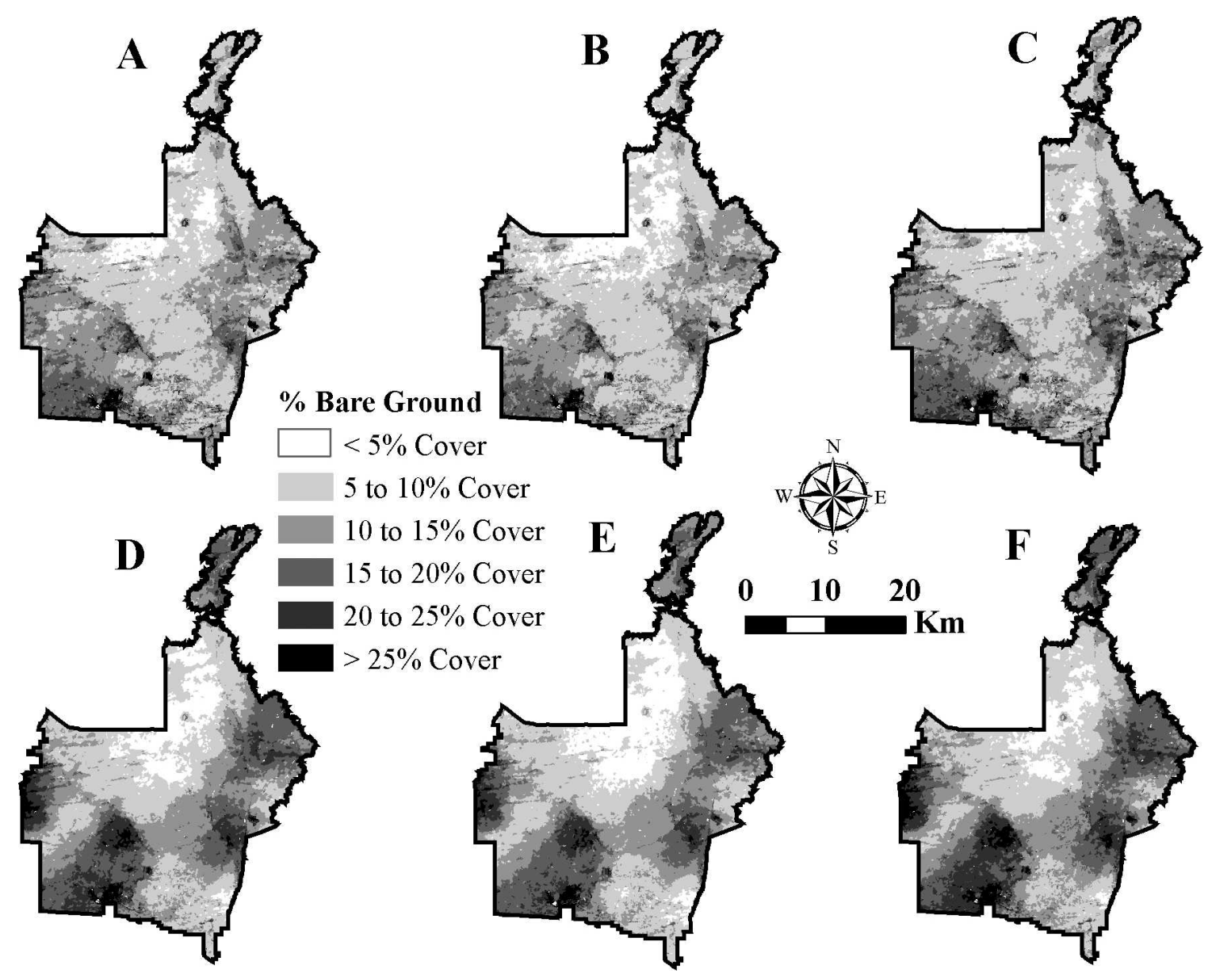

Figure 7. Spatial predictions of percent bare ground cover in the Wildhorse area. A, Generalized least-squares (GLS) regression prediction. B, GLS lower 95\% confidence interval limit. C, GLS upper 95\% confidence interval limit. D, Regression kriging (RK) prediction. E, RK lower 95\% confidence interval limit. F, RK upper 95\% confidence interval limit.

associated with the bare ground and cheatgrass maps, these predictions should still be useful in assessing large changes in cover across the study area.

In large part, the high RMSE for these variables was a result of the low correlation between the sample locations and the satellite imagery, and several factors could be contributing to this. First, spatial error in the location of pixels or imprecision in location of the field sampling locations can affect the strength of the correlation (Peleg and Anderson 2002; Weber 2006). Weber (2006) found that high-resolution satellite imagery (i.e., 2.4-m resolution) produced more accurate land cover classifications for rangelands than Landsat Thematic Mapper imagery in part because of the increased precision of georeferencing image pixels with high-resolution imagery.

Second, the differences in dates from when the field data and imagery were collected may have impacted field-to-image correlations. Ideally, to maximize the field-to-image correlation for either RK or GLS, the field data would have been collected at the same time that the satellite imagery was acquired. Site condition can vary year to year and even within a year, depending on differences in precipitation, temperature, management, and disturbance. Often, however, it is logistically difficult to collect all the required field data even within a single season, especially for large study areas. If the goal is to establish the relationship between field and image data but not to make spatial predictions, then multiple images could be used that correspond to the dates that the field data were collected. For spatial predictions, however, this approach would not work because there would be no way to determine which image data to use for the pixels between the sample locations. In this situation, the best approach may be to identify areas that have experienced significant changes between when the field and image data were collected and exclude them from the regression analysis. This was the case for the Wildhorse Allotment, where I excluded sites that burned following field data collection. Other, more subtle differences in site condition may be more difficult to control for and can affect the strength of the relationship between the field and image data and inflate the variogram nugget.

Finally, the low number of points measured per transect at each field site may not be a good approximation of the conditions at that site. The nugget of the variogram model represents the portion of the observed variance in the field observations that cannot be explained by spatial autocorrelation (i.e., by distance). One determinant of the magnitude of the nugget is the variability in the samples (Bailey and Gatrell 1995). Sample variability can have two causes: 1) natural variability in the system and 2) variability introduced by factors that obscure the relationship between the field and image data, such as imprecise sampling methods or site differences resulting 


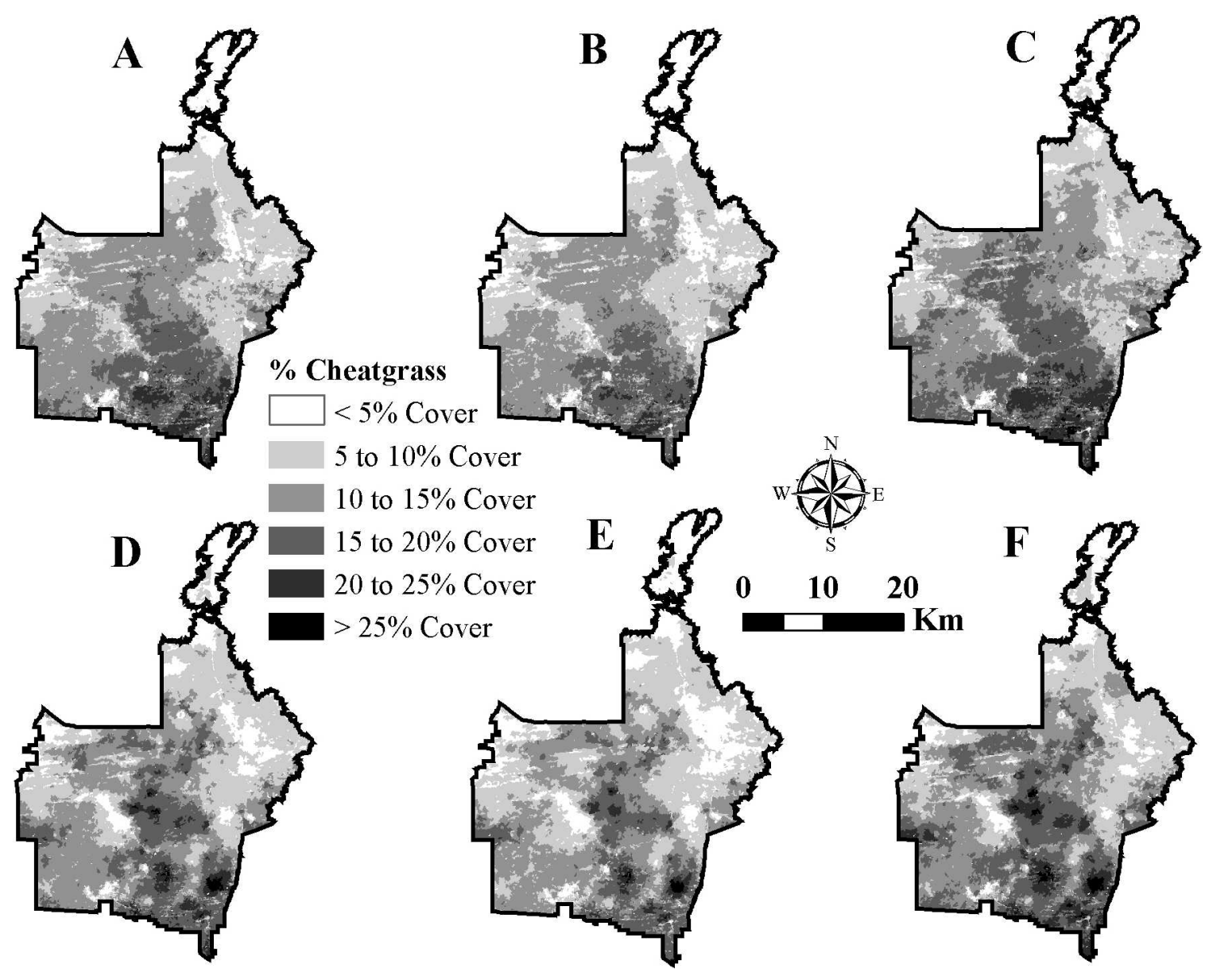

Figure 8. Spatial predictions of percent cheatgrass cover in the Wildhorse area. A, Generalized least-squares (GLS) regression prediction. B, GLS lower 95\% confidence interval limit. C, GLS upper 95\% confidence interval limit. D, Regression kriging (RK) prediction. E, RK lower 95\% confidence interval limit. F, RK upper $95 \%$ confidence interval limit.

from time lags between field and image data collection. The first cause cannot be directly controlled but can be addressed in part through measures like defining system bounds to minimize variability or employing stratification. This could have been done in modeling the percent shrub cover attribute by first classifying the satellite image to discriminate between sites with shrub cover and those without and then performing the RK only for those areas with shrub cover.

The second cause, however, is under the control of the investigator. Methods involving kriging argue for the use of precise methods and strong measures to minimize interobserver variability. The field measurements used in this study were made with only 50 measurements taken to calculate percent cover. The finest cover measurement discernible using this method was $2 \%$, and the placement of the transects may not have been located such that it was representative of the site. The more closely measurements reflect the true condition of the sample site, the smaller the variogram nugget and the more accurate the results of the kriged predictions. In practice, though, the precision and accuracy of measurements at each site must be weighed against the need to have a lot of sites sampled to estimate empirical variograms.

Knowing a priori whether RK will yield significantly better results than GLS regression is difficult to determine. Variograms of GLS model residuals, though, are relatively easy to construct as long as coordinate values are associated with the measurements at each field point. If significant spatial structure exists in the residuals, manifest as a low nugget-to-sill ratio and a long semivariance range (Kravchenko 2003), then RK should provide better predictions than GLS regression. Empirical variograms with scattered points that have no discernible pattern indicate a lack of spatial structure, and in these cases RK generally will not perform any better than GLS and may actually lower crossvalidation results because of overfitting of the data.

With any statistical technique, understanding the limits of the inference space is important. Inference space refers to the limits of inferences, or generalizations, that can be made from a set of observations or data (Dixon and Garrett 1994) and includes the range of parameter values as well as the spatial extent of the inference. In terms of parameter (i.e., dependent variable) values, predictions made beyond the range of values that were sampled in the field may be suspect because assumptions must be made that the relationship between the dependent variable and the independent variables is the same outside the range of values sampled. For the variables considered in this study, limits of inference for the variables are set by the minimum and maximum values observed for each of these variables in the field (Table 1). This highlights the importance of sampling across the full range of conditions if the objective is to produce predictive maps across landscapes. 
The spatial limits of inference are determined by both the distribution of the sample points and the spatial autocorrelation of the variable. For a variable with a high degree of spatial autocorrelation (i.e., having a long range in a variogram model), the spatial inference space would be larger than for a variable having low spatial autocorrelation. Thus, the empirical variograms and variance estimates from RK are useful in determining the spatial limits of inference from regression modeling.

The spatial maps of confidence generated from RK are different from those of GLS regression because the confidence decreases with distance from the field observation points until the range of the variogram is reached. For locations beyond the range of the residuals variogram, the confidence of $\mathrm{RK}$ is the same as that of the GLS regression predictions.

\section{IMPLICATIONS}

Regression kriging is a potentially powerful data-driven tool for making spatial predictions of rangeland condition attributes. Like standard regression techniques, RK leverages the correlation between field observations and remotely sensed data to make predictions over large landscapes. Its advantage over standard regression techniques, however, comes in that it exploits the spatial autocorrelation of field observations to improve predictions, thereby making better use of expensive and difficult-to-collect field data. Predictions from RK are especially suitable for landscape-level assessment and planning efforts because the uncertainty in the predictions and how it changes through space can be quantified. The ability to create maps depicting how confidence changes with distance to observation points is a significant benefit of the regression kriging approach. Maps of the RK variances show more directly the effects of proximity to the sample locations and can be useful in determining how adequate sampling was for the kriging aspect of regression kriging or where additional samples might be located to improve or increase consistency of predictions by suggesting additional places where sampling might occur.

\section{ACKNOWLEDGMENTS}

G. Mann and J. Russel from the Shoshone District BLM provided me with the field data for this study. M. McCarthy, K. Colson, and K. DiChristina assisted in data collection during 2008. B. Maurer, R. Unnasch, G. Roloff, S. Riley, J. Qi, and three anonymous reviewers provided thoughtful reviews and editorial comments on this manuscript.

\section{LITERATURE CITED}

Addink, E. A., S. M. de Jong, and E. J. Pebesma. 2007. The importance of scale in object-based mapping of vegetation parameters with hyperspectral imagery. Photogrammetric Engineering and Remote Sensing 73:905-912.

BAATZ, M., AND A. SCHÄPE. 2000. Multiresolution segmentation-an optimization approach for high quality multi-scale image segmentation. In: J. Strobl, T. Blaschke, and G. Griesebner [EDS.]. Angewandte Geographische Informationsverarbeitung XII. Heidelberg, Germany: Wichmann-Verlag, p. 12-23.

Bailey, T. C., and A. C. Gatrell. 1995. Interactive spatial data analysis. Reading, MA, USA: Addison-Wesley. $432 \mathrm{p}$.
BedeLL, T. E. 1998. Glossary of terms used in range management. 4th ed. Denver, CO, USA: Society for Range Management, Direct Press. $32 p$.

Berterretche, M., A. T. Hudak, W. B. Cohen, T. K. Maiersperger, S. T. Gower, and J. L. Dungan. 2005. Comparison of regression and geostatistical methods for mapping leaf area index (LAI) with Landsat ETM+ data over a boreal forest. Remote Sensing of the Environment 96:49-61.

Blaschke, T., M. Conradi, and S. Lang. 2002. Multi-scale image analysis for ecological monitoring of heterogeneous, small structured landscapes. Proceedings of SPIE 4545:35-44.

Burnett, C., AND T. BLASCHKE. 2003. A multi-scale segmentation/object relationship modeling methodology for landscape analysis. Ecological Modelling 168:233-249.

Chavez, P. S., JR. 1996. Image-based atmospheric corrections-revisited and improved. Photogrammetric Engineering and Remote Sensing 62:1025-1036.

Connelly, J. W., M. A. Schroeder, A. R. Sands, and C. E. Braun. 2000. Guidelines to manage sage grouse populations and their habitats. Wildlife Society Bulletin 28:967-985

Crawford, J. A., R. A. Olson, N. E. West, J. C. Mosley, M. A. Schroeder, T. D. Whitson, R. F. Miller, M. A. Gregg, and C. S. Boyd. 2004. Ecology and management of sage-grouse and sage-grouse habitat. Journal of Range Management 57:2-19.

Cressie, N. 1993. Statistics for spatial data. Rev. ed. New York, NY, USA: John Wiley and Sons. 928 p.

Crist, E. P., and R. J. Kauth. 1986. The tasseled cap de-mystified. Photogrammetric Engineering and Remote Sensing 52:81-86.

DEuTSCH, C. V. 1996. Correcting for negative weights in ordinary kriging. Computers \& Geosciences 22:765-773.

Deutsch, C. V., And A. G. Journel. 1998. GSLIB: geostatistical software library and user's guide. New York, NY, USA: Oxford University Press. $369 p$.

Dixon, P. M., and K. A. GarRett. 1994. Statistical issues for field experimenters. In: R. J. Kendall and T. E. Lacher, Jr. [EDS.]. Wildlife toxicology and population modeling: integrated studies of agroecosystems. Boca Raton, FL, USA: CRC Press. p. 439-450.

Dymond, J. R., P. R. Stephens, P. F. Newsome, and R. H. Wilde. 1992. Percentage vegetation cover of a degrading rangeland from SPOT. International Journal of Remote Sensing 13:1999-2007.

Feitosa, R. Q., G. A. O. P. Costa, T. B. Cazes, and B. Feluo. 2006. A genetic approach for the automatic adaptation of segmentation parameters. Proceedings of the First International Conference on Object-Based Image Analysis; 4 July 2006; Salzburg University, Salzburg, Austria. Available at: http://www.isprs.org/ proceedings/XXXVI/4\%2DC42/papers.htm. Accessed 30 March 2010.

FoRSTER, B. C. 1980. Urban residential ground cover using Landsat digital data. Photogrammetric Engineering and Remote Sensing 46:547-558.

Fortin, M. J., AND M. Dale. 2005. Spatial analysis: a guide for ecologists. Cambridge, United Kingdom: Cambridge University Press. 380 p.

Fox, J. 2002. An R and S-PLUS companion to applied regression. Thousand Oaks, CA, USA: Sage. 328 p.

GoovaERTS, P. 1997. Geostatistics for natural resource evaluation. New York, NY, USA: Oxford University Press. $496 \mathrm{p}$.

Hengl, T., G. B. M. Heuvelink, And D. G. Rossiter. 2007. About regression-kriging: from equations to case studies. Computers \& Geosciences 33:1301-1315.

Hengl, T., G. B. M. Heuvelink, And A. Stein. 2004. A generic framework for spatial prediction of soil variables based on regression-kriging. Geoderma 120:75-93.

Herrick, J. E., J. W. Van Zee, K. M. Havstad, L. M. Burkett, and W. G. Whitford. 2005. Monitoring manual for grassland, shrubland, and savanna ecosystems. Las Cruces, NM, USA: USDA-ARS Jornada Experimental Range. 236 p.

HoleCHEK, J. L. 1988. An approach for setting stocking rate. Rangelands 10:10-14.

Holechek, J. L., C. H. Pieper, And C. H. Herbel. 2001. Range management: principles and practices. Upper Saddle River, NJ, USA: Prentice Hall. 542 p.

Hudak, A. T., M. A. Lefsky, W. B. Cohen, and M. BerterRetche. 2002. Integration of lidar and Landsat ETM+ data for estimating and mapping forest canopy height. Remote Sensing of the Environment 82:397-416.

Hunt, E. R., JR., J. H. Everitt, J. C. Ritchie, M. S. Moran, T. D. Booth, G. L. Anderson, P. E. Clark, and M. S. Seyfried. 2003. Applications and research using remote sensing for rangeland management. Photogrammetric Engineering and Remote Sensing 69:675-693. 
Hunt, E. R., JR., And B. A. Miyake. 2006. Comparison of stocking rates from remote sensing and geospatial data. Rangeland Ecology \& Management 59:11-18.

Jensen, J. R. 1996. Introductory digital image processing. 2nd ed. Upper Saddle River, NJ, USA: Prentice Hall. 318 p.

KaRL, J. W., and B. A. Maurer. 2010. Spatial dependence of predictions from image segmentation: a variogram-based method to determine appropriate scales for producing land-management information. Ecological Informatics. Available online at: http://dx.doi.org/10.1016/j.ecoinf.2010.02.004. Accessed 30 March 2010.

Knotters, M., D. J. Brus, and J. H. Oude Voshaar. 1995. A comparison of kriging, co-kriging and kriging combined with regression for spatial interpolation of horizon depth with censored observations. Geoderma 67:227-246.

KRAVChenKo, A. N. 2003. Influence of spatial structure on accuracy of interpolation methods. Soil Science Society of America Journal 67:1564-1571.

KRIGE, D. G. 1966. Two-dimensional weighted moving average trend surfaces for ore-evaluation. Journal of the South Africa Institute of Mining and Metallurgy 66:13-38.

LARK, R. M. 2002. Optimized spatial sampling of soil for estimation of the variogram by maximum likelihood. Geoderma 105:49-80.

LLoYd, C. D. 2005. Assessing the effect of integrating elevation data into the estimation of monthly precipitation in Great Britain. Journal of Hydrology 308:128-150.

Lopez-Granados, F., M. Jurado-Exposito, J. Pena-Barragan, and L. Garcia-Torres. 2005. Using geostatistical and remote sensing approaches for mapping soil properties. European Journal of Agronomy 23:279-289.

Marsett, R. C., J. QI, P. Heilman, S. H. Beidenbender, M. C. Watson, S. Amer, M. Weltz, D. GoodRich, AND R. MARSETt. 2006. Remote sensing for grassland management in the arid southwest. Rangeland Ecology \& Management 59:530-540.

McKenzie, N., and P. Ryan. 1999. Spatial prediction of soil properties using environmental correlation. Geoderma 89:67-94.

Nash, M. S., A. Toorman, P. J. Wierenga, A. Gutjahr, and G. L. Cunningham. 1992. Estimation of vegetative cover in an arid rangeland based on soil-moisture using cokriging. Soil Science 154:25-36.

National Research Council. 1994. Rangeland health: new methods to classify, inventory, and monitor rangelands. Washington, DC, USA: National Academies Press. $180 \mathrm{p}$.

NavuluR, K. 2007. Multi-spectral image analysis using the object-oriented paradigm. Boca Raton, FL, USA: CRC Press, Taylor and Francis Group. 165 p.

Odeh, I., AND A. B. McBratney. 1994. Spatial prediction of soil properties from landform attributes derived from a digital elevation model. Geoderma 63:197-214.

Odeh, I., A. B. McBratney, and D. Chittleborough. 1995. Further results on prediction of soil properties from terrain attributes: heterotopic cokriging and regression kriging. Geoderma 67:215-226.
Pebesma, E. J. 2004. Multivariable geostatistics in S: the gstat package. Computers \& Geosciences 30:683-691.

Peleg, K., and G. L. Anderson. 2002. FFT regression and cross-noise reduction for comparing images in remote sensing. International Journal of Remote Sensing 23:2097-2124.

Pellant, M., P. Shaver, D. A. Pyke, and J. E. Herrick. 2005. Interpreting indicators of rangeland health. Ver. 4. Denver, CO, USA: US Department of the Interior, Bureau of Land Management, National Science and Technology Center. Technical Reference 1734-6. 122 p.

Pickup, G., G. N. Bastin, and V. H. Chewings. 1994. Remote-sensing-based condition assessment for nonequilibrium rangelands under large-scale commercial grazing. Ecological Applications 4:497-517.

Pinheiro, J. C., And D. M. Bates. 2000. Mixed-effects models in S and S-PLUS. New York, NY, USA: Springer-Verlag. 528 p.

Qı, J., R. Marsett, P. Hellman, S. Biedenbender, M. S. Moran, and D. Goodrich. 2002. RANGES improves satellite-based information and land cover assessments in southwest United States. EOS, Transactions of the American Geophysical Union 83:601, 605-606.

RICE, J. A. 2007. Mathematical statistics and data analysis. 3rd ed. Belmont, CA, USA: Thompson Brooks/Cole. 688 p.

Scнотт, J. R. 2007. Remote sensing: the image chain approach. 2nd ed. New York, NY, USA: Oxford University Press. 688 p.

TobleR, W. R. 1970. A computer movie simulating urban growth in the Detroit region. Economic Geography 46:234-240.

us Department of Agriculture-Natural Resources Conservation Service. 2003. Soil survey geographic (SSURGO) database for Blaine County area, Idaho. Fort Worth, TX, USA: USDA Natural Resources Conservation Service. 198 p.

WeBER, K. T. 2006. Challenges of integrating geospatial technologies into rangeland research and management. Rangeland Ecology and Management 59:38-43.

Webster, R., And M. A. Oliver. 1991. Sample adequately to estimate variograms of soil properties. European Journal of Soil Science 43:177-192.

Webster, R., and M. A. Oliver. 2007. Geostatistics for environmental scientists. Hoboken, NJ, USA: John Wiley and Sons. $331 \mathrm{p}$.

Wu, J. 1999. Hierarchy and scaling: extrapolating information along a scaling ladder. Canadian Journal of Remote Sensing 25:367-380.

Wu, J., AND J. L. DAviD. 2002. A spatially explicit hierarchical approach to modeling complex ecological systems: theory and applications. Ecological Modelling 153:7-26.

Yemefack, M., D. G. Rossiter, and R. Nuomgang. 2005. Multi-scale characterization of soil variability within an agricultural landscape mosaic system in southern Cameroon. Geoderma 125:117-143. 